pipettes is divided into centimetres. The blood is filled into the pipettes up to the fifth division, and the column of blood is aspirated some little distance up the tube in order to obviate any desiccation of the blood at the orifice.

The tubes are easily cleaned by means of a fine wire. They are then washed out successively with distilled water, alcohol, and ether. When the ether evaporates the tubes are warmed in the hand or in an incubator and are then ready for use. In addition to these ordinary coagulation tubes Mr. Dean has, at Professor Wright's suggestion, made tubes provided with a mixing chamber. By employing these latter it is possible not only to study the effects of various additions upon the coagulability of a particular blood but also to repeat at any moment the classical experiments in connexion with blood coagulation. For this purpose it is only necessary to fill an aliquot part-say a sixth of the tubewith the fluid whose influence on coagulation it is desired to elicit. Into the tubes thus primed a column of blood of the usual length is introduced. Mixture of the fluid with the blood is effected by aspirating the contents of the tube into the mixing chamber and then immediately blowing them down in an unbroken column into the stem of the pipette. The coagulation time obtained with the mixed blood is, of course, compared with that elicited for the unmixed blood. The coagulation-inhibiting properties of decalcifying substances (such as soluble oxalates and citrates), or of additions of neutral salts, or of leech extract can readily be demonstrated by this method. To do this it is only necessary to prime the tubes (say up to the first division) with a 1 per cent. solution of oxalate of soda, a from 3 to 5 per cent. solution of citrate of soda, a from 20 to 25 per cent. solution of sodium chloride or magnesium sulphate, or, lastly, a decoction of a leech which has been sliced up after it has been killed by alcohol.

\section{THE PRESENT SANITARY CONDITION OF FLORENCE.}

BY W. W. BALDWIN, M.D.

IN a communication to THE LANCET of Dec. 19th, 1891, upon the Sanitation of Florence and Sir Douglas Galton's Report I stated that, in consequence of sanitary reforms, the death-rate of the city had decreased from 36 per 1000 in 1870 to 25 per 1000 in 1890 . It was not then known, however, what steps would be taken towards carrying out Sir Douglas Galton's suggestions in regard to the further sanitation of the city. I am glad to say that much good work in this direction has been accomplished by the authorities since that report was made, more work is in hand, and it has been decided "to continue these reforms until Florence shall be above reproach in sanitary matters."

The new sewers have been pushed towards completion in the old drain quarters, and in good time they will entirely replace the old, shallow, irregular, leaky drains, which are more or less filled with deposit. The square section is being changed to the oval form, the ancient flat-bottomed house drains have been abolished, and well-trapped, air-tight, tubular metal or glazed earthenware pipes of prescribed pattern are being substituted. The same system has been adopted for the house waste water-pipes, and any communication between the two has been forbidden. Many wells have been closed, and the remainder will be shut up as soon as possible. A thorough and efficient houseto.house sanitary inspection has been established by law, and various illegal overflows from cesspits have been discovered and stopped. This necessitates a far more frequent removal of nightsoil than formerly, and at the same time ensures its free dilution with water. The old clumsy handpumping apparatus, miscalled votatura inodora, is being rapidly set aside by an efficient steam service which is practically inodorous. This new macchina a vapore has the further advantage of completely emptying the cesspits in two minutes, whereas the old machine required an hour or more to pump out the liquid contents, always leaving more or less deposit behind; in the meantime the whole neighbourhood was nauseated, if not poisoned, by the smells.

Many unsightly "common conveniences" have been removed, while the more conspicuous ones have been covered by decent modern iron structures. There is still room for improvement in this particular; but the authorities are hampered by the prejudices of an Italian populace who lack our northern standard of modesty, having been accustorned from time immemorial to satisfy nature's wants in public at any and every moment. No doubt the general free consumption of thin, sour native wine, which is strongly diuretic, may have had much influence in creating this canine habit. It is related that one sindaco of Florence, influenced by foreign complaints, commanded that all these too-convenient nuisances should be removed. He was besieged in his palace by a mob of enraged citizens, who perpetrated unspeakable things in the anterooms, threatening to return every day until their luogi commodi should be restored. This was done forthwith. The gallery from which the present water-supply is derived has been extended by 250 metres. The town rubbish deposits which existed in the vicinity of this extension have been removed and a sufficient tract of land in the neighbourhood is kept in grass and guarded from pollution, as was promised. Unfortunately, the long-continued drought which Florence had suffered, in common with the whole of Europe, caused scarcity of water, culminating in September and October, which necessitated great economy in its use. The public drinking fountains were only allowed to flow during a part of the morning and the sewers were not flushed. In consequence there were universal complaints of bad smells and lack of water, for which, obviously enough, there could be no remedy except abundant rain. Sensational reports were published in the London daily papers of a water famine in Florence, and it was claimed that its state of public health was very bad. Truly the smells were bad enough, and while no water famine ever existed a much longer continuance of the drought might have caused one owing to the fact that the reserve supply had been drawn off to cleanse the reservoir and renew the filters.

As regards the public health, probably owing to the extraordinary precautions taken by the authorities to cleanse and disinfect the city, added to the sanitary reforms which had already been carried out, the mortality returns for July, August, September, and October were the lowest ever recorded in Florence, the average death-rate during this time being 1752 per 1000. That for November promises to be equally low. In spite of the very high death-rate in Januarv and February caused by the influenza epidemic (above 30 per 1000) the mortality returns for 1893 will probably show the lowest average annual death-rate ever recorded in this city. At present, after copious rain, we have a great abundance of water, the sewers are well flushed, and the evil smells are no longer complained of. At last an exhaustive and admirable report upon the Garfagniana Springs, by a committee of competent engineers, has been accepted by the municipality, and as soon as the necessary capital can be raised this splendid undertaking will be inaugurated, which, when finished, will furnish Florence with above 40,000 cubic metres daily of the purest and most wholesome water. This source is absolutely unfailing. I purpose visiting these springs in the near future.

It has always been the custom, no doubt, to blame the municipality for any and every misfortune which may overtake a city, including great natural disasters such as earthquakes and drought. Otherwise what can be the explanation of the startling proposition made by the correspondent of a leading London daily paper to chain the Florentine authorities to the open sewers as punishment for evil smells undoubtedly caused by the drought? These gentlemen have certainly made a fair and praiseworthy record in sanitary reform under great discouragement and against bitter opposition since Sir Douglas Galton made his startling and unexpectedly unfavourable report. It is no holiday task to modernise a mediæval city with its vast fortress-like palaces and narrow, tortuous streets, and Florence is poor as well as old.

Florence, Nov. 17 th.

St. John Ambulance Assocration.-Whe presentation of medallions and certificates to the students belonging to classes held in the City and Port of London, Bloomsbury, Islington, Highbury, and the North-east and East of London was made by the Duchess of Bedford at the People's Palace, Mile-end, on the 22nd ult. Nearly 400 students received awards. 